\title{
Consumer policy and corporate policy in the $\mathrm{EU}$
}

\author{
Günter Verheugen
}

(C) VOe 2012

Consumer policy and corporate policy are subjects increasingly at the centre of European politics. The starting point is the same in both cases as it is notably evident in the EU's 2020 strategy for growth and jobs. Consumers are a major economic power. Consumer spending in the EU produces up to $56 \%$ of total economic output. Restraint or stimulation of consumption affects economic development and may have a major impact on the global economy as particularly the situation of the Federal Republic of Germany shows. But even more, without the corresponding behaviour of consumers, the desired sustainability of the European economy will not be achieved. It is now generally accepted that consumer policy has to be an essential element of every growth strategy.

The same applies to corporate policy. Again, the basic idea is clear and simple. In a liberal economic order, which is founded on entrepreneurship and protection of property, it may not be the responsibility of the state itself to act as an entrepreneur, for example, to achieve employment objectives. The policy task is rather to create a framework that releases and rewards entrepreneurship, but also prevents market failure reliably. Therefore, it is not just about freedom to trade, but also its limitations. Currently, companies have to consider a legal framework, which not only focuses on economic optimization, but also includes society's social and environmental needs.

Consumer policy and corporate policy are classic crosssectional matters. They affect virtually all areas of policy. European legislation designed, for instance, to reduce the

Studies in History, Sociology and Political Science. 1999-2004 member (Enlargement) and 2004-2010 Vice-president (Enterprise and Industry) of the European Commission. Currently Managing Director of The European Experience Company GmbH and Honorary Professor at the European University Viadrina Frankfurt (Oder)

Günter Verheugen, The European Experience Company GmbH ( $\square)$

Am Neuen Garten 45, D-14469 Potsdam, Germany

E-Mail: <gv@european-experience.de>
CO2-emissions of motor vehicles causes a wave of innovations in the automotive industry and therefore enhances its international competitiveness. At the same time this strategy creates costs, which the consumer has to bear. He might even accept these costs when he is kept informed and is aware that higher acquisition costs are offset in the long run by lower operating costs. The interests of producers and consumers may not always harmonize as easily as in this case. For instance, with regard to food safety or labelling of ingredients or the exploitation of patents in pharmaceutical research, or even transparency to the costs of energy supply diverse interests collide and conflict resolution can be very tedious.

Companies and their associations tend to dramatize the compliance costs with respect to regulations on consumer protection and they are used to lament the threat of their competitiveness with much ado. Conversely, consumer organizations tend to place the industry under suspicion to fool consumers in general. Politics has to meet this challenge as a balancing act. It has to take into account both, the businesses' interests and the consumers' interests and simultaneously it has to provide a balance of interests both sides can live with. There is no principled decision guidance in this regard. A weighing of interests has to be made in each individual case. In any case, a priority of consumer interests is not explicitly stated in politics.

Historically, shifts in the conflict between consumer policy and business policy have been observed, often in favour of consumers. The original EEC did not even know the subject of consumer protection. It is not mentioned at all in the Treaty of Rome. A first program on consumer protection was presented by the EEC in 1975, without a proper legal basis, but based on others existing legal bases. The Cassis de Dijon judgment of the CJEU in 1979, ground-breaking in many respects, highlighted consumer protection as a general interest. In today's current Treaty on the Functioning of the EU 
(TFEU) consumer protection is a cross-sectional matter and requires the Commission to pursue its proposals for European legislation at a "high level" of consumer protection. These provisions express a modified social consciousness - Consumer protection is not an exotic playground any more, but a key policy area moving up in the strategies of governments and political parties. Politicians like to distinguish themselves as consumer advocates that's promising a score in public in a rather easy way. In Brussels, the Commission has ensured to establish a kind of equality of arms between the industry and consumers with significant funding. In the environmental sector, conditions have already been reversed. If there was ever such a way that the industry could affect the public opinion and thus the policies in their favour by spending "big money", that does not apply anymore. Costliest industry campaigns do not reach the efficacy of a single press release from Greenpeace.

Even in a larger political context, the European institutions have been promoting consumer protection more than previously. When the proposed Constitutional Treaty failed in referendums in France and The Netherlands in 2005 and the continuing political crisis began, the strategic response from Brussels was a reorientation of EU policy on the immediate needs of citizens. Especially the Commission and the Parliament placed more emphasis on the communication of immediate benefits their decisions have on individuals. But it is not that simple in the EU, and the idea readily came to mind to emphasize the fact that all 500 million EU citizens are consumers. A striking example of this new style of politics was the act of reducing roaming charges for mobile phones enforced by the Commission. Certainly, there was regulatory concern over this approach even within the Commission, but the huge PR success of this action speaks for itself.

Nevertheless we ought not to speak of a flawless consumer policy. The main reason for that fact is the totally fragmented allocation of responsibilities within the Commission. Indeed, the Commissioner for Consumer Protection is responsible for general consumer policy and long-term strategy, but he does not draft the decisive legal acts. Other Commissioners are in charge of the areas of telecommunications, internal market, financial services, transport (e.g. Regulations on passengers' rights), product safety, etc. Even the general Consumer Rights Directive is under responsibility of the Commissioner of Justice. Each initiative thus requires a significant internal need of coordination causing major frictional losses. At the moment the Commission is in a lively debate held on the possible introduction of class actions. It is very unlikely that the Commission may agree on a proposal for a legal act in the foreseeable future in this highly important question of law although the Directorate General for Competition, even if operating in a very independent way, has already proposed class actions in the area of antitrust.
On 22.05.2012, the Commission presented its strategy for consumer policy in the form of a "European Consumer Agenda". There is absolutely nothing to argue against the four priorities of this agenda: Consumer safety, knowledge and education, enforcement and securing redress (Alternative Dispute Resolution) and aligning policy to societal change. It remains to be seen what concrete steps announced for the five mentioned key sectors (food, energy, financial services transport and digital) may follow. Corporate policy of the EU suffers from the same structural weaknesses as consumer protection policy. The most important legislation for the industry is not proposed by the Commissioner for Enterprise and Industry, but comes from the fields of environment, health, energy, research, etc. Even if the consumer interest in the EU maybe seen as relatively homogenous (but also with numerous limitations as European consumers' habits are also shaped by diversity, like everything else), it is impossible to find such homogenity in business interests. Almost $99 \%$ of the 24 million enterprises in the EU are small or micro enterprises, which did not participate in the internal market at all. A handicraft business active on a local level has different interests than a global player. The Commission has therefore concluded that their corporate policy in the strict sense has to be a policy for small and medium-sized enterprises. The problem in this regard is that the responsibilities in practical questions often lie with the Member States. For large enterprises in the EU, the branching and detailed rules of the EU are usually not the problem. In contrast to the public opinion, primarily dominated by consumer and environmental organizations, the Chemicals Regulation REACH - one of the largest and most complex laws of economic history - has never been a problem for the chemistry giants. But on the other hand down-stream users, small and medium-sized enterprises, have faced enormous compliance difficulties. In contrast, the bulk of European enterprises is quite indifferent to such developments, for example, the EU competition policy that is getting increasingly problematic for large European enterprises. The excessive fines in antitrust law practice by now could be mentioned in this regard - a consequence of the decision that the parent company is fully responsible for the misconduct of legally independent subsidiaries. Likewise constitutional deficits in the EU antitrust policy can be regarded critically also because of the fact that compliance programs at the highest standard and appropriate practice of management are not taken into account when penalising antitrust violations.

In summary we may stress that the structure and functioning of the Commission is neither favouring a coherent consumer policy nor a coherent corporate policy. Therefore, it would be highly appreciated, if the debate on the reform of the EU already set in motion was also including the question on how the EU is actually doing policy, who personally is doing policy and how it is controlled. 